University of South Florida

DIGITAL COMMONS

Digital Commons @ University of

@ UNIVERSITY OF SOUTH FLORIDA

South Florida

Educational and Psychological Studies Faculty

Publications

Educational and Psychological Studies

$9-2012$

\title{
Searching for a Needle in a Haystack: Indications of Social Justice Among Aspiring Leaders
}

Vonzell Agosto

University of South Florida, vagosto@usf.edu

Zorka Karanxha

University of South Florida, karanxha@usf.edu

Follow this and additional works at: https://digitalcommons.usf.edu/esf_facpub

Part of the Educational Administration and Supervision Commons

\section{Scholar Commons Citation}

Agosto, Vonzell and Karanxha, Zorka, "Searching for a Needle in a Haystack: Indications of Social Justice Among Aspiring Leaders" (2012). Educational and Psychological Studies Faculty Publications. 10.

https://digitalcommons.usf.edu/esf_facpub/10

This Article is brought to you for free and open access by the Educational and Psychological Studies at Digital Commons @ University of South Florida. It has been accepted for inclusion in Educational and Psychological Studies Faculty Publications by an authorized administrator of Digital Commons @ University of South Florida. For more information, please contact digitalcommons@usf.edu. 


\section{Rapid \#: -6066042 usf.hosts.atlas-sys.com/TPA}

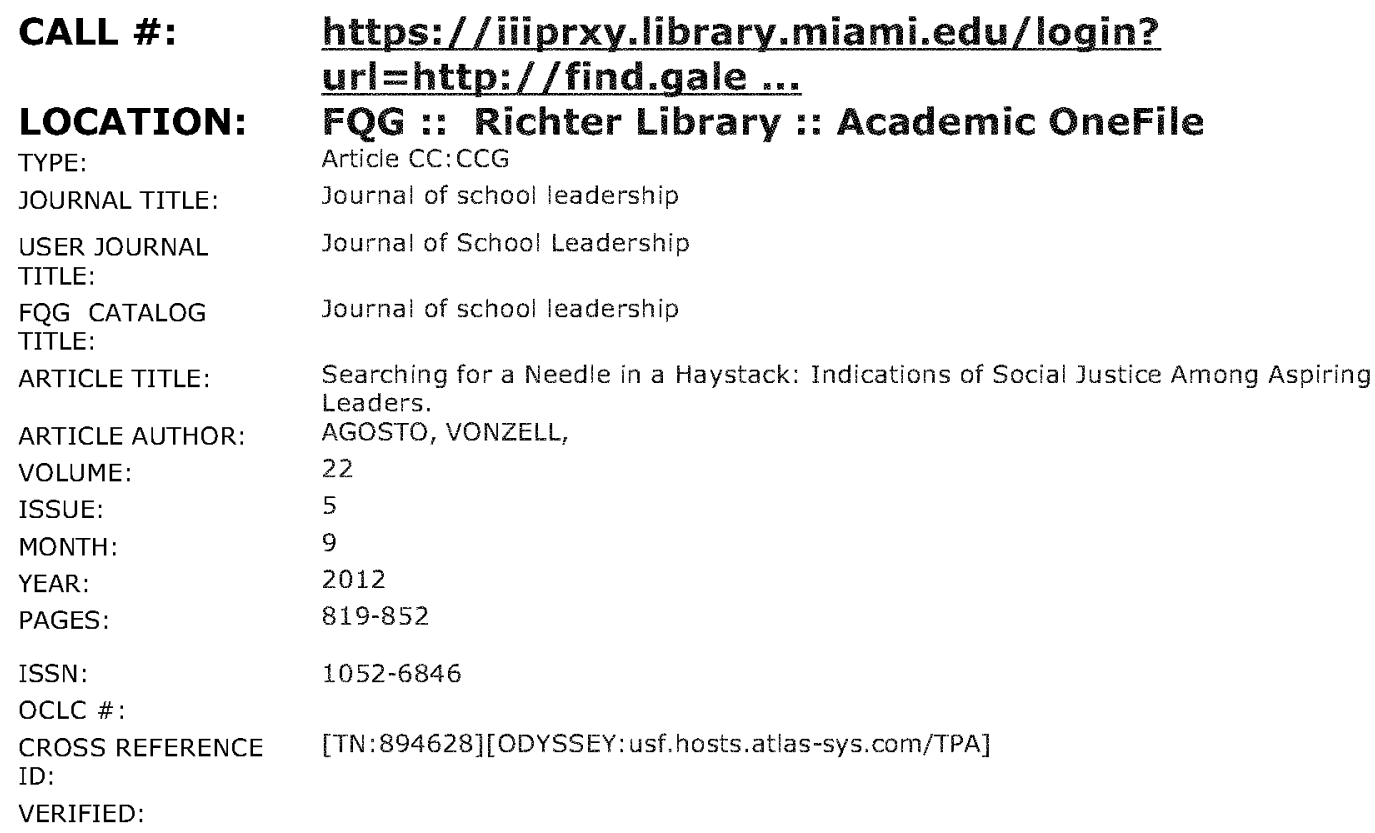




\title{
Searching for a Needle in a Haystack: Indications of Social Justice Among Aspiring Leaders
}

\begin{abstract}
We conducted a content analysis of 34 statements of interest submitted by applicants applying for admission to an education leadership preparation program. The purpose of the analysis was to understand their orientations toward social justice. Using Kumashiro's (2000) and Apple's (2001) discussions of antioppressive education, we identified three practices in the candidates' treatment of the writing prompt concerning leadership related to Othering: ignoring, marginalizing, and mentioning. The fourth practice-embodying, or evidencing through practice, a social justice orientation-we identified in statements submitted by a few applicants $(n=7)$. This article centers on the analysis of the applications of these seven candidates through the metaphor needle in a haystack. Through conducting a secondary-level analysis to extrapolate the knowledge, skills, and dispositions of critical literacy and elicit our collective perceptions of what constitutes social justice leadership, we found the social justice orientations-"or needles"-for which we searched. This self-reflexive approach to research reflects the model of program evaluation that we are developing called self-assessment for equity. We provide recommendations for faculty interested in improving their program's capacity to identify, prepare, and sustain social justice leadership.
\end{abstract}

In this article, we engage a self-reflexive qualitative research design to examine 34 applicants' statements of interest for indications of a social justice/antioppressive orientation. These 34 statements were submitted as part of the admission process into an educational leadership and policy studies master's degree program and analyzed after all decisions regarding

Address correspondence to Vonzell Agosto, PhD, Department of Educational Leadership and Policy Studies, University of South Florida, 4202 East Fowler, Tampa, FL 33620. E-mail: vagosto@usf.edu. 
the rejection and acceptance of these applicants were finalized. Applicants were directed to respond to the following prompt: "Describe your a) leadership experience related to aspects of the mission statement, b) interest in the program, and c) goals related to the ideas of equity and diversity." The purpose of the content analysis was twofold: (1) to gain an understanding of the social justice orientations among applicants so that the program can better identify them to recruit them and serve them and (2) to explicate our own social justice orientation so that, as faculty involved in deciding which candidates are accepted or rejected into the program, we can enter the process self-aware of what we value and discount while encouraging these kinds of disclosures as we make decisions that affect students and the program.

We use the idiom searching for a needle in a haystack as a metaphor for our inquiry into the social justice indications within applicants' statements of interest. Searching for a needle in a haystack is often tedious and difficult work yet necessary when that for which you are searching is camouflaged and embedded. Searching reflects our processes of interpretation and analysis. The "needle" refers to a social justice orientation indicated in the statements related to the leadership practice of the applicants. The "haystack" refers to the content of all 34 applicants' statements situated in the field of social justice leadership. In searching for a needle in a haystack, we used a critical theoretical framework to help make evident what was before us yet difficult to isolate, as social justice is elusive. We used the three types of knowledge identified by Apple (2001) and the four approaches to antioppressive education that Kumashiro (2000) identified as recurring in the work of educators and educational researchers concerned with issues of oppression. Their discussions of oppressive or unjust practices are situated in the context of $\mathrm{K}-12$ schooling. As such, their concepts and recommendations are relevant to our analysis of personal statements that primarily concern leadership experiences of teachers working in Grades $\mathrm{K}-12$. There are seven statements that we deemed exemplary, for they included most, if not all, aspects of the prompt to which applicants were instructed to write and they indicated social justice orientations in their leadership practice (embodied). We subjected the statements to a secondary-level analysis to explicate the social justice orientations represented in these documents. Focusing on the seven allows us to look at those underrepresented in our program to better understand them so that we might better recruit and serve applicants who are oriented toward social justice.

There is a paucity of empirical research on social justice leadership, social justice preparation, and program evaluation conducive to that preparation. To address this gap in the literature, we discuss our development 
of a model, called self-assessment for equity (SAFE), and its implementation through this study of applicants' statements concerning social justice leadership. This study also brings attention to the iterative and interpretive processes of reading the statements, conducting qualitative research, and assessing equity in social justice leadership preparation programs. This self-reflexive approach and focus on seven exemplary statements helps to center ourselves as interpreters in the process of candidate selection and center social justice leadership in practice. This intentional laboring to center ourselves in research and programmatic decisions affecting social justice helps us to articulate the tacit nature of our work, examine our sensibilities regarding equity and justice, increase the transparency of our work, and model an image of faculty leadership in which equity and justice are central. This combined approach of research and program assessment helps bring transparency, alignment, and intentionality to a program that aspires to advocate, model, and support social justice leadership.

The selection of applicants (prospective students) oriented toward social justice into educational leadership preparation programs is recommended in the literature on building the social justice capacity of programs (Chenoweth, Carr, \& Ruhl, 2002; McKenzie et al., 2008). McKenzie and colleagues (2008) assert that for students without some foundational capacity, a program would have to devote significant time to raising their consciousness about social justice, a demand that would be difficult to satisfy given the relatively brief duration of a leadership preparation program. After identifying applicants oriented toward social justice/antioppressive leadership, we can monitor how they are received and treated, as well as how they experience and influence the program and their work environments. Understanding the antioppressive approaches used by applicants can inform curriculum decisions about what types of knowledge to emphasize, where to focus efforts (to foster, sustain, or expand understandings of social justice leadership), and how well preparation programs are doing in admitting candidates who reflect diversity, depth, and range in their social justice orientations. As faculty invested in an improved program of leadership preparation, we view the selection process as part of the effort to prepare an equitably excellent program.

We work from the following assumptions: First, program improvement can occur more efficiently and equitably when we seek and advocate for students who also envision themselves as having a role in improving education as a prong of social change toward increasingly more just and humane relations, locally and globally. Second, the influence, experiences, and capacities (knowledge, skills, dispositions) that applicants (who are oriented toward an ethic of justice) bring to the curriculum, instruction, 
and policy of the program and $\mathrm{K}-12$ schools are assets. Third, statements of interests written by aspiring educational leaders can be interpreted for indications of a social justice orientation.

Programs preparing leaders are a significant factor in social, economic, and cultural change or stasis since educational leaders help to (de)legitimate the knowledge, skills, and dispositions that reproduce and/or transform an oppressive social order. "Who will lead schools may be one of the most critical challenges and one of the most important opportunities to influence social justice" (Cambron-McCabe \& McCarthy, 2005, p. 208). Our response to the query posed by George Counts (1932) on whether schools dare build a new social order is "yes, but not alone." The work of faculty in educational leadership is implicated in the state of the educational system-past, present, and future. Leadership preparation programs influence the leadership corps through their decisions about whom to accept or reject.

\section{REVIEW OF THE LITERATURE}

We use the terms social justice and antioppression as counterweights to remind us what are we working for justice (for all to survive and flourish) and what are we working against (injustice, oppression). The relationship of oppression to justice is explicated by Iris M. Young's (1990) enabling conception of justice, in which injustice is characterized by the disabling constraints of oppression and domination. She argues that to secure justice, faces of oppression must be challenged (i.e., violence, cultural imperialism, marginalization, exploitation, powerlessness). A considerable part of the literature emphasizes the importance of understanding the potential harmful effects of the inequalities as a fundamental component toward creating socially just environments (Brooks \& Miles, 2008; Cambron-McCabe \& Scheurich, 2008; Capper, Theoharis, \& Sebastian, 2006; Dantley \& Tillman, 2006; Furman \& Shields, 2005; Hafner, 2006; Theoharis, 2007).

McKenzie and colleagues (2008) suggest the necessity for candidates to possess some awareness of their own as well as others' social beliefs, biases, and prejudices upon entrance in the principalship preparation program. Many who advocate leadership preparation for social justice argue that to act on the inequalities and truly be a leader for social justice, one must (1) believe that the inequalities are unjust, unwarranted, and a function of various factors within the school and broader community and (2) be willing to restructure the organization (McKenzie et al., 2008; 
Skrla, Scheurich, Garcia, \& Nolly, 2004; Theoharis, 2007). The literature on teacher preparation and, more recently, leadership preparation supports the view that it is more advantageous to recruit and select students who have beliefs and values that are congruent with those necessary for promoting justice and equity rather than expecting that deeply held belief systems that compete with notions of justice and equity will be converted into practice that is ethically oriented toward justice in $\mathrm{K}-12$ schools. According to Haberman and Post (1998), a key to improving schooling for youth in poverty is in the selection of teachers based on the premise that selection is more important than training, while "training is useful only for those with appropriate dispositions" (p. 103). Since many prospective teachers "not only lack these understandings [of social inequity] but reject information regarding social inequity ... more work on recruiting particular kinds of students into teaching must be done" (Ladson-Billings, 1995, p. 477). Not only are knowledge bases that support teaching and leading across diversity needed in preparation programs, aspiring teachers and leaders need to see their educators actively engaged in trying to correct social injustice (Pritchy-Smith, 1998).

Regarding educational leadership preparation, Chenewoth and colleagues (2002) suggest, as the main criterion for selection, that faculty at each institution develop "a philosophy that is used as criteria for decisions on admissions" and that candidates be "admitted based on the compatibility with program philosophy" (pp. 10-11). To ensure that values are internalized by school leaders, there needs to be strict and stringent selection criteria established at institutions preparing school leaders (McKenzie et al., 2008), and departments as well as institutions and organizations should share a unified front (McKenzie et al., 2008; Murphy \& Vriesenga, 2006; Oliva, Anderson, \& Byng, 2010) to infuse social justice in all aspects of the program. According to McKenzie and colleagues (2008), not selecting students who already lean toward a social justice orientation will mean that considerable territory must be covered in the 2 short years of the principal preparation program. To create the social justice-oriented changes that are sorely needed in schools, we agree with the "recommendation that we must select individuals who already have a propensity, at a minimum, to critically question the inequities found in schools" (p. 118). "With this advantage, preparation programs can much more quickly move the candidates to learn how to become advocates and leaders of change in schools that will successfully serve students of color, poverty, linguistic differences, (dis)abilities, and various sexual orientations" (p. 118).

The persistence of social inequities (pertaining to classism, racism, sexism, homophobia, and ableism) that negatively affect students, families, and 
communities and contribute to achievement gaps instills a sense of urgency among many educators to respond to the call for equity. A response to this call for equity is evident by the heightened focus on social justice as a centerpiece of leadership preparation programs (Furman \& Shields, 2005; Marshall \& Oliva, 2006, 2010). Despite the increased attention to social justice leadership, research shows that social justice issues still reside in the margins of principal preparation programs while the focus remains on traditional topics, such as school law, organizational theory, supervision, and finance (Brooks \& Miles, 2008; Jean-Marie, Normore, \& Brooks, 2009; Shoho, 2006). Leaders who challenge the status quo that sustains inequity are especially inspiring given the overarching political climate of conservatism and the degree of risk taking involved (Lugg \& Shoho, 2006) that makes social justice advocacy "risky business for school administrators" (p. 205), teachers, and tenure-earning professors (e.g., Allan \& Estler, 2005). We concur with Shoho and colleagues (2005), who assert that espoused theories that challenge the status quo are meaningless for students unless professors of educational leadership put these theories to action.

\section{HISTORICAL CONTEXT}

The Department of Educational Leadership and Policy Studies (DELPS) has undergone recent changes in faculty membership, leadership, and curriculum. The mission statement of our department is as follows:

The purpose of DELPS is to prepare ethical, compassionate, public intellectuals to become critical and transformative leaders committed to social justice in America's schools. The primary means to achieve our purpose are: collaborative inquiry, culturally relevant pedagogy and public deliberation on the historical and perennial issues that confound public education in our nation. We expect our faculty and students to make value-added contributions to national, state, district and school-level policy and purposeful inclusive practices that lead to social justice and learning for all.

With approval from the Institutional Review Board, we (the authors) set out to examine the processes associated with the master's degree program-from selection to admission, curriculum, pedagogy, and exit-while modeling and conceptualizing SAFE. Department-wide faculty participation in its development and implementation will be invited gradually; however, in this first year, we are guiding the development of this model with support from leadership in the department and in the college. 


\section{SELF-ASSESSMENT FOR EQUITY}

SAFE, a multiphase internal review process, is being developed and piloted by us as faculty members to assess the alignment between the department's mission statement and equity across all aspects of the program that affect the student experience from application (candidate selection) to enrollment (curriculum) to exit (learning outcomes). It is shaped by and shapes the contributions that we make to the department and leadership program. SAFE coincides with departmental efforts to achieve, sustain, and exceed current institutional status, program accreditation, leadership standards, and students' pass rate on the leadership certification exam. Through SAFE, we aim to improve the master's degree program in educational leadership preparation and provide a model for programs similarly inspired to facilitate equitably excellent and socially just education.

In conceptualizing this research-based model of SAFE, we borrow the K-12 equity audit framework from Skrla and colleagues (2004) and the framework for social justice leadership preparation presented by Capper and colleagues (2006). We modify them where necessary to fit the assessment needs of the leadership preparation program in which we work. SAFE represents internal praxis: "engaging in a cycle of theory, application, evaluation, reflection, and then back to theory" (Freire, 1998, p. 75) to continuously assess whether DELPS's actions reflect a social justice orientation. We use this self-assessment model to assist our leadership preparation program in conducting an internal assessment or selfassessment that attends to the social justice ethic of a program through a process that models praxis in the effort to prepare leaders to facilitate equity and educational excellence across schools, students, their families, and communities.

\section{APPLICANT SELECTION CYCLES}

In the fall of 2009 , the faculty assumed the responsibility of selecting applicants whom they would recommend to the graduate school for admission into the master's degree program. In previous years, this process was the purview of the department's academic advisor who accepted applicants on a first come, first served basis with a rolling application. The preferred requirements are a 3.0 grade point average or a Graduate Record Examination score of 1000, 2 or more years of certified teaching experience, and a professional educator's teaching license. 
Historically, students were accepted until the carrying capacity of the program was met.

After the first selection cycle, we noticed arbitrariness in the process, a disproportional rejection of underrepresented candidates (of color), and a lack of consensus and discussion concerning selection criteria (Agosto, Karanxha, \& Bellara, 2010). As part of SAFE, we undertook the examination of the application process conducted by the master's committee. We aimed to answer the question that we as a committee were strained in our efforts to engage: What and whose knowledge, capacities, and experiences do we find valuable and likely to benefit the program as students and K-12 schools as leaders? To help answer this question and attend to the larger purpose of assessing equity in the structures of the program, we began to develop a process of applicant selection (Karanxha, Agosto, \& Bellara, 2010).

\section{PROMPT}

We drafted, and the committee agreed to pilot, a prompt requesting that candidates submit a written statement of interest in which they describe their (1) leadership experience related to aspects of the mission statement, (2) interest in the program, and (3) goals related to the ideas of equity and diversity (see Appendix A). The prompt asked applicants to write about equity related to leadership and the program's mission statement. The prompt was reviewed by the committee, and there was agreement to pilot it during the next application cycle. Thus, the prompt included two directives that we expected would elicit discussions of leadership related to social equity, diversity, and social justice (i.e., describe leadership experience related to the mission statement and describe goals related to equity and diversity). The statement was one artifact along with professional letters of recommendation that faculty used to evaluate the potential success and contributions of the applicants to the program, colleagues, $\mathrm{K}-12$ schools, and educational leadership. Through their statements, we aimed to understand the applicants' knowledge, capacities (skills, dispositions), and experiences concerning social justice so that we could make informed decisions about whom we select and why we select some and reject others. This included attention to how students engaged with the mission statement (which components) and what/whose knowledge, skills, dispositions, and experiences were (de) valued by the selection committee. We constructed a rubric to help guide faculty in rating the statements and provide a record of impressions that 
could be used by committee members in cases requiring deliberation over whether to admit or reject an applicant.

\section{RUBRIC}

The rubric consisted of statements that would help in interpreting or deciphering applicants' application materials (statement of interest, letters of recommendation) for diverse knowledge, skills, and dispositions thought valuable to the field and to the program's learning environment (see Appendix B). In part, the rubric was modeled after recommendations made in the university's equity report on how to recruit and retain a more racially and ethnically diverse faculty and staff. Of the 15 statements in the rubric, there are 4 that overtly draw from social justice discourse on leadership related to diversity and advocacy: "Has experienced a leadership role with students, families, or organizations historically underserved in schools," "Speaks two or more languages and/or has 2 or more cultural backgrounds/identities," "Advocates justice for traditionally marginalized groups of students," and "Demonstrates resiliency (persisting despite unusual hardships, circumstances, disadvantages)." Some criteria can reflect either privilege or commitment to social justice (i.e., "Has worked or volunteered outside the United States"). The rubric allowed faculty to record their impressions of candidates gleaned through the application materials submitted. From a social justice perspective, "the faculty selecting the students need to ensure, though, that they are generally looking for the same qualities in the prospective students and that there is some faculty work on interrater reliability" (McKenzie et al., 2008, p. 121).

The faculty piloted the rubric to establish interrater reliability, using two randomly selected statements of interest submitted by early applicants who identified as White females. The results suggested fidelity of the instrument and a sufficient demonstration of common interpretations. However, in our previous selection cycle, the master's degree committee's divergence of opinions on the quality of candidates primarily centered on the selection/rejection of students of color (students from underrepresented racial and ethnic groups in higher education and leadership). Additionally, there is no guarantee that the rubric will not be used by committee members to reject students with a social justice orientation. It is an asset-based approach, and those qualities thought evident by the committee member should be checked; those with more checks are more likely to be admitted, in theory. 


\section{CONCEPTUAL FRAMEWORK}

We situate this research in the tradition of critical education studies (Apple, 2000), bridging critical social theory (Young, 1990) with social justice leadership into a critical social justice leadership praxis (Foster, 1986; Ryan \& Rottman, 2007), an advocacy approach (Bloom \& Erlandson, 2003; Lather, 1991) with antioppressive intentions. According to Ryan and Rottman (2007), some of the key assumptions of critical social justice leadership include the following:

- "Social institutions are human creations."

- "Societal institutions continuously disadvantage some communities more than others."

- "Patterns of dis/advantage are not always visible."

- "Social justice involves more than resource distribution and economics."

- "Social justice is not consistent with the idea of just desert."

- "Social justice favours equity over particular versions of equality."

- "Social justice involves all aspects of education."

- "Social justice calls for hope." (pp. 12-16)

Social justice leadership preparation then entails that leaders "make issues of race, class, gender, disability, sexual orientation, and other historically and currently marginalizing conditions in the U.S. central to their advocacy, leadership practices and vision" (Theoharis, 2007, p. 223). Examples of supporting text from the seven applicants' statements interpreted as utilizing a critical social justice/antioppressive leadership framework provide miniportraits of the aforementioned assumptions, types of knowledge, skills, dispositions, and experiences of the candidates and their treatment of the mission statement. This is in contrast to the other 27 statements, which were limited to expressions of theory, such as mentioning, ignoring, and marginalizing, which fall short of the praxis approach to social justice leadership that we espouse.

The practice of mentioning is described by Michael Apple (2001) in his discussion of the incorporation of marginalized cultures in the curriculum through textbooks. In the process of mentioning, the marginalized knowledge of political minority groups is included without a shift in the ideological frameworks or elaboration from the perspectives of those marginalized. Apple describes mentioning as including the contributions of political minority groups as "add-ons" about the culture and history of the "other" (p. v). We extend Apple's concept of mentioning as a process of Othering that is illustrated through the treatment of social justice (a major theme of the mission statement) in many of the personal statements submitted by applicants. Critical literacy counters the effects of mention- 
ing and similar discursive moves (i.e., ignoring, marginalizing). According to Apple, there are three types of knowledge that students learn to gain critical literacy: discrete knowledge (knowledge that), practical knowledge (knowledge how to), and dispositional knowledge (knowledge to). These types of knowledge are used socially and educationally and include higher-order thinking skills and critical skills of inquiry. We use these types of knowledge as an interpretive framework to help expose the social justice orientations embodied (lived) in the leadership experiences that applicants describe in their statements.

Dantley and Tillman (2010) suggest that "Kumashiro's work can serve as a foundation for a leadership practice that recognizes and addresses, in a socially just manner, the various ways that students can be systematically oppressed in schools" (p. 21). Kumashiro (2000) describes four approaches that are generally used by educators and educational researchers in conceptualizing the nature of oppression and the curricula, pedagogies, and policies needed to bring about change. His use of the term Other is in reference to those groups that are traditionally marginalized in society, and due to oppressive structures "are other than the norm" (p. 26). The approaches are as follows: education for the Other, education about the Other, education that is critical of privileging and Othering, and education that changes students and society. Kumashiro suggests that educators and educational researchers integrate all four approaches. We do so in relation to educational leadership and leadership preparation.

\section{EDUCATION FOR THE OTHER}

Oppression involves harm from action and inaction (failure to act antioppressively), substandard conditions or treatment, and perceptions (deficit view or low expectations). In contrast, change includes providing helpful and affirming spaces with culturally sensitive disposition, pedagogies, and accommodations, as well as acknowledging differences. Those who do not work against oppression are complicit. The focus of education for the Other tends to focus on the treatment of individuals and/or single expressions of oppression. Kumashiro warns that to focus on the marginalization of the Other and not on the role of privileging in the process of Othering implies that the Other is the problem and so ignores the construction of oppression beyond interpersonal relationships.

\section{EDUCATION ABOUT THE OTHER}

Researchers have pointed to two ways of thinking that can lead to the construction of the Other or further harm by another or by self: through 
either educator inaction (failure to intervene in oppression) or the internalization of negative messages. The first derives from the construction of knowledge about what/whom society defines as "normal" (the way things generally are) and what is normative (the way things ought to be). Such constructions of knowledge teach Otherness by inference and in contrast to the norm. The second kind of thinking is the distorted or misleading (i.e., biased) understandings of groups. Antioppressive approaches such as inclusion and the integration of the Other into the curriculum bring visibility and challenge stereotypical thinking. However, the limitation of this approach is that it tends to essentialize the Other, as students begin to perceive that their knowledge about the Other is complete rather than partial. Generally, this approach is used to fulfill a gap in knowledge about "them," "these," or "those" students rather than to disrupt the dominant knowledge that constructs the Other or bring about structural or institutional change.

\section{EDUCATION THAT IS CRITICAL OF PRIVILEGING AND OTHERING}

Educators and students need to examine not only how some groups and identities are Othered "but also how some groups are favored, normalized, privileged, as well as how this dual process is legitimized" (Kumashiro, 2000 , pp. 35-36). The role of antioppressive institutions and educators is to critique the structural and ideological forces that Other as well as to interrogate their complicity with these forces. Critiques of Othering and privileging coupled with transformation are central to this approach. Raising critical consciousness and a sense of empowerment among educators and students supports this approach and reflects the tenets of critical pedagogy. However, the assumption that reason alone leads to transformation is based on rationalist thinking that can simultaneously undermine the experience, knowledge, and transformative strategies of the Other (Ellsworth, 1989).

\section{EDUCATION THAT CHANGES STUDENTS AND SOCIETY}

Kumashiro (2000) describes the poststructural influence on theorizing oppression as a discourse that frames how people feel and act especially in response to the repetition of harmful discourses or histories. Addressing oppression from a poststructural lens then requires not only an awareness of the ways in which multiple forms of oppression work together but also antioppressive responses-for instance, by laboring to disrupt the recitation or repetition of harmful information through its supplementation with less harmful information. Furthermore, according to Kumashiro, labor that leads to change requires the work of many. 
Our use of the concept Other takes into account both Kumashiro's and Apple's discussions of Othering as a process of oppression that occurs in text and context when people and practices ignore, mention, or marginalize (Young, 1990) groups, knowledge, and values. Our search for indicators of social justice is thus a search for critical literacy represented by disruptive knowledge, skills, and dispositions that are embodied in the labor toward antioppressive/social justice education. What Kumashiro (2000) asks of educational theory, we continue to ask of educational leadership and leaders-ourselves included. "Are 'education,' 'teaching,' and 'learning' framed by theories, disciplines, and perspectives that make only certain ways of thinking possible, only certain kinds of questions askable?" (p. 42).

\section{METHOD}

We conducted a content analysis of personal statements of interest ( $n$ $=34$ ) submitted by applicants to the educational leadership preparation program during the fall of 2010 to understand the social justice orientations among our applicants. We removed the names of applicants from the statements to ensure anonymity and reduce our bias that could come through assumptions about names in relation to the gender and race of the applicants. We collected and analyzed approximately 135 pages of text. Coders included us and a doctoral student, who helped with the triangulation of the data and the control/reduction of bias and who brought another perspective. Initially, each coder read and highlighted sections of the statements reflective of our a priori codes, which were lifted from the mission statement, values, and the prompt to which applicants were instructed to respond. We organized, stored, retrieved, and reduced the data through coding and compound coding using a color-coded system. We first coded two statements and discussed the interpretations that led us to code as we had. We identified repetitions, patterns, and themes that surfaced through initial coding, compound coding, and annotations. The themes of interest were deductive categories related to the mission and values of the program, as well as characteristics of social justice leadership discussed in the literature and conceptual framework (ignoring, marginalizing, mentioning, and embodying).

In the secondary level of analysis of statements that indicated a social justice orientation, we used Kumashiro's (2000) framework to glean the use of antioppressive/social justice approaches to education. Additionally, Apple's (2001) description of three knowledges assisted in achieving a more nuanced interpretation of the content and context reflecting the 
critical literacy that supports social justice leadership. This interpretive framework reflects our orientations, and the interpretive process enables us to discuss and understand our perceptions and values concerning social justice, as well as those of the applicants. The findings, including the committee's reactions to the 34 statements, begin to poke at the question "What types of knowledge do we value among applicants who aspire to enter an educational leadership preparation program?"

\section{FINDINGS}

Overall, there were four main themes present across the entire sample: ignoring, mentioning, marginalizing, and embodying. Approximately half the statements ( $n=16$ of 34 ) reflected one of first three categories, which are examples of Othering. The term social justice appears twice in the mission statement, and the prompt offered two opportunities for applicants to engage in discourse that may be unwelcome or unspoken in their current settings. Even then, few students engaged in a social justice discourse or used the term. We were not surprised that many applicants ( $n=27$ of 34) did not address the question of equity in the prompt or the concept of social justice. In our experiences with the student population (which tends to be a racially and gendered homogeneous group-i.e., White females) that we inherit from the local context, we have met few who were familiar with the term social justice or expressive of critical perspectives. Of those who addressed the prompt (including the question of equity), there were a few $(n=7)$ whom we ( $n=2$ of 3 coders) viewed as exemplary.

\section{MAJORITY REPORT: LITTLE TO NO INDICATION OF SOCIAL JUSTICE ETHIC IN PRACTICE}

Many applicants ignored the prompt altogether, although the directions explicitly instructed them to address it in relation to their leadership experience. Some aspects of the prompt were ignored in all but a few statements (i.e., culturally relevant pedagogy). Another common practice was mentioning (Apple, 2000) the mission statement without engaging its major concepts (i.e., public intellectual) or elaborating on it. A statement that all three raters agreed was not a good example did mention social justice but reflected superficial attention to the mission statement, including the comment "I will not . . . watch injustice occur." However, there was no discussion or indication that the applicant was aware of how the leadership experience described in the statement mattered to issues of justice or 
injustice. The marginalization of social justice occurred through reductive comments, such as social justice is "what the department preaches"; or, social justice was mentioned as if it were insignificant or irrelevant to the discussion.

Many ignored the term social justice altogether (even though it is the only term that occurs twice in the mission statement). Some who ignored the term but not the mission statement engaged in repetition and therefore privileged some values from it. For instance, the value of collaboration was discussed most often and was characterized as a practice related to accountability, occurring among teachers as horizontal teams. Few applicants engaged other forms of collaboration, such as that with the community (families, organizations). In several examples of collaboration with community, the focus was on businesses donating money rather than on work with nonprofit and/or community-based organizations. There were several statements in which applicants stated that their practice aligned with the mission statement. For instance, one applicant described a leadership experience as "the essence of the mission statement." In most cases, we were not convinced of this alignment, as the examples tended to reflect a single value in the mission statement and failed to explicate the relevance of their practice to (in)justice. The practices of ignoring, marginalizing, and mentioning worked to Other social justice in our mission statement and its associated values.

Approximately half the applicants provided statements that the coders agreed had neither substantively attended to the mission statement nor indicated a critical social justice orientation. Yet, 28 of 34 (82\%) applicants gained admission. If our primary criterion was a social justice ethic, we would have admitted fewer. However, aside from the social justice ethic, other criteria were considered (letters of recommendation, diversity in areas of certification, years of experience). The findings raise the following questions: (1) How are educational disparities (reflected by the opportunity and achievement gap) exacerbated by a lack of diverse socially just leaders? (2) How are faculty in educational leadership programs implicated in the advancement of educational disparity and parity?

Our efforts eventually led us to the question that typically follows a collaborative search for a needle in the haystack: How did we miss it? As if looking for a needle in a haystack, we sifted through the exemplary statements to understand our applicants, ourselves, and our program. With a long-term goal of program improvement in mind, this work informs the ongoing question of how to identify and serve social justice-oriented applicants so that they serve all students. 


\section{THE MINORITY (RE)PORTRAIT: SEVERAL INDICATIONS OF A SOCIAL JUSTICE ETHIC IN PRACTICE}

In our second round of coding, we sought to assess the leadership qualities discussed in the statements through the guiding question related to Apple's (2000) discussion of knowledge types: What types of knowledge are imparted by these statements related to social justice? The coders agreed that $18(53 \%)$ statements attended to most, if not all, aspects of the prompt (mission statement, leadership experience, values, goals, and attention to diversity in relation to equity). From those 18 statements, we selected 7 that were exemplary, for they integrated most, if not all, of the components of the prompt in a substantive way to reflect what we perceived as an ethical orientation toward social justice that was either expressed or implied and embodied in practice they described with supporting detail (evidenced). The following miniportraits of embodiment highlight aspects of critical literacy pronounced in the statements that are reflective of the mission statement and values of DELPS.

Miniportrait of Embodiment 1: Critique. Applicant 1 described working in an overcrowded classroom as a first-year teacher of students who were diagnosed as having severe emotional disorders. She described her experience as transformational in that it led her to realize that she "was prejudiced, selfish and ignorant." She recalled how students labeled disabled were treated in a system that "did not know what to do with them." In describing her leadership development, she appropriated the deficit discourse on disability: "I've never lived inside the 'box' known as the norm. I am ready to take on this greater role and move forward thoughtful ideas and paradigm shifting philosophies that are needed to transform this crippled system known as education." Her beliefs and goal statements were integrated as she expressed readiness to change the field "before many of our children are permanently lost."

Some of the knowledge, skills, and dispositions that we perceived through her statement were criticality coupled with advocacy and compassion. This "seasoned teacher" described her work with students, peers, novice teachers, and parents ("by teaching them how to advocate and communicate with and for their children"). After 12 years of teaching "special education students" in economically challenged areas, she reflected on her first year. "No educational training could have primed my heart or mind for the cumulative folders on ... the experiences they had faced; the abuse and neglect." Now, as an applicant with 16 years of teaching experience, she is critical of self, schools, and society. 
Miniportrait of Embodiment 2: Cultural knowledge, equity, and excellence. Applicant 2 described his role as a "migrant advocate" for high school students. As a "bridge" person who is a former migrant student, he appeared to understand the lack of opportunities for migrant parents to pursue education. He emphasized the cultural knowledge and understanding that he gained from migrant families, which helped him to educate school faculty on students' culture and which enabled the school "to increase the migrant student's [sic] graduation rate above 65\%." The statement, titled "Cultural Knowledge," and the detailed description of the cultures among the migrant population in his school suggest the applicant's respect and value for cultural diversity.

The skills, knowledge, and dispositions that we noted were as follows: cultural bridging, cultural knowledge, personal knowledge and experience, and compassion. These qualities were evident throughout his advocacy work with migrant students at his school. As a public intellectual, he advocates for social justice issues through his ability to communicate in various spaces (school, migrant families, and community at large) to increase students' graduation rate. He interviewed families to determine their specific needs, and he worked with teachers to address students' individual needs. His efforts and commitment to connecting migrant families with their children's schools and other services for the purposes of improving their lives are characteristics of "bridge people" (Merchant \& Shoho, 2010).

Miniportrait of Embodiment 3: Advocacy, care, and the awareness of vulnerability. Although a math teacher, Applicant 3 described working with adult immigrant students who were learning English as a second or other language. The narrative contextualized the lives of the "foreigner," the average student's workload, and the challenge this posed for socialization and study. The applicant described the routine of teaching and the absence of higher-order thinking skills. The focus of the curriculum on social skills "bothered" the candidate, who began to question its relevance. A math lesson on percentages was enlightening, as the applicant inquired of the students, "What is FICA?" The applicant realized the vulnerability of the students, especially Latinas, and attributed it to a deficiency in money management skills. In response, she developed a language curriculum that responded to students' work demands and integrated math instruction. This experience inspired Applicant 3 to propose a class for $\mathrm{K}-12$ students learning English that would bridge the connections among school, students, their parents, and community. Some of the knowledge, skills, and dispositions that we perceived through this applicant's personal statement 
included an ability to probe the experiences of students and design curriculum that empowers students to have more control in their lives. The applicant demonstrated an awareness of the intersectionality of students' various social positions (nationality, race, immigrant status, gender, and class) shaping their experiences. For instance, she noted the differences among female immigrants from Europe versus Latin America.

Miniportrait of Embodiment 4: Advocacy and inclusion. With more than 20 years of instructional experience, Applicant 4 was intent on improving the instruction of students learning English as another language. A major purpose driving the curricular and pedagogical practice of Applicant 4 was the promotion of cultural knowledge about students learning English. A personal interest translated into a professional commitment as the applicant sought endorsement to teach students learning English. This allowed the applicant to work as a resource teacher to assure that " $A L L$ " students are included and not "just sitting in the corner doing coloring sheets." This applicant framed her leadership experience as having to do with providing equal access to the curriculum with accommodations, using creativity and collaborative teaching to advocate for inclusion. The knowledge, skills, and dispositions that we perceived in the applicant's statement included cultural knowledge, advocacy, and an ethical disposition. These qualities were informed by a belief in the value of cultural knowledge to inform the selection and implementation of strategies for improving access and instruction. The skills, knowledge, and dispositions combined to provide inspiration, ease, direction, and a sense of urgency to teachers.

Miniportrait of Embodiment 5: Achievement gap. Applicant 5 described her first year of teaching at a Renaissance School (98\% free and reduced-price lunch, D grade) as "an eye opening experience." She was critical of the previous leadership at the school and the "inconsistency" that had "pushed many parents away from our school community." She displayed an asset-based approach toward the parents and community and took a leadership role in organizing and teaching in the "Science Saturday School" and "Extended Day" programs. Determined to do "whatever it takes," she was "proud to say" that she and her colleagues "made a difference every day." They raised the school's grade and "did their best to close the achievement gap." She stressed the need "to be vigilant in continuing to close this gap." Her involvement in multiple programs helped her become a leader at the school. As a leader, she challenged the status quo and critiqued the disparities in the type of knowledge and educational opportunities to which students from low income communities have access. She engaged students in "projects" that "lead to higher order thinking." 
The skills, knowledge, and dispositions that we perceived were as follows: criticality, advocacy for the marginalized, and vigilance (inequities). She was critical of the educational system and how the "drill and kill" approach to education affected creativity, which in her view "has left the classroom." She was critical of the deprofessionalization of teaching and noted that "in a push to have the 'smartest,' fact spewing, students, we have forgotten what it really means to be 'smart." She identified a "very large problem that is prevalent in our country's educational system . . the 'Achievement Gap."

Miniportrait of Embodiment 6: Ministry and youth advocacy. The leadership of this applicant was enacted in formal and informal educational spaces. She described her work with a youth ministry from a holistic view of their success: spiritual, emotional, athletic, and academic. The youth ministry program involved communication and relationships between parents and the larger community to support and encourage youth. Additionally, she believed herself to be committed to social justice in American schools and has a goal to establish working relationships with the schools attended by the youth. An imperative element of the academic leadership that she provides to youth is "cultural relevance" so that what is being done is working for the population served. The candidate invoked concerns for equity and excellence in education coupled with goals to provide culturally relevant information to parents so that they are prepared to advocate for their children's success and equality in education. This candidate described a research agenda on issues of race, culture, and gender. The skills, knowledge, and dispositions that we perceived were as follows: cultural consciousness, mentorship, advocacy, and an ethic of social justice based on a sense of morality that recognizes difference and the need to understand the challenges youth face. A teacher for 3 years, Applicant 6 stressed the importance of education and the role of adults in diminishing the probability of failure. According to this applicant, helping children regardless of their background and family challenges was a matter of providing creative approaches to education that are personalized and compassionate.

Miniportrait of Embodiment 7: Racial and cultural diversity in higher education. This applicant described her first year as a Spanish language teacher in a middle school and how she founded and coordinated a performance group whose purpose was to expose students to various cultural literature and traditions and, in the process, "alleviate ignorance of race and culture" among students and their families. Later on, in a different role, she served as a bridge to connect teachers, students, and parents. She transformed the lives of students who were the first persons in their families to 
receive a college education. This applicant also started a program to create a support system and continue her mentoring of the girls, guiding them to enter college. Some of the skills, dispositions, and knowledge that we noted were as follows: substantial knowledge and respect for cultural diversity, transformational leadership, mentoring, care, and compassion. This applicant, with 12 years of teaching experience, recognized the need for valuing diversity and took action by creating programs that made a positive difference in students' educational outcomes. Her understanding of the importance of access to higher education for females of traditionally marginalized groups led her to provide an environment conducive to their success. The determination, creativity, resiliency, insistence, and care of this candidate led several of her students to higher education.

\section{COMPOSITE OF THE EXEMPLARY APPLICANTS}

Of the seven applicants with exemplary statements, six were female and one was male. The average teaching experience for the group was 8.5 years, ranging from 3 to 20 years. Three identified ethnically as Hispanic, two as African American, and two racially as White (i.e., no ethnic attribution identified). They worked with students who live with families who are migrant workers, have individualized special education plans, are from working-class or low-income communities, and/or are learning English as a second language. In other words, they worked with students from historically marginalized groups in the U.S. system of education and other institutions. The numerous knowledge, skills, and dispositions that constitute critical literacy and its application by applicants in their respective contexts with students, families, and communities were varied among these candidates and reflected many of the themes and values in the mission statement and values of DELPS. As we serve individuals and collectives, it is helpful to also find the overlap in these individual expressions to inform our deliberations over how to serve both.

A composite of the candidates' knowledge, skills, and dispositions provides insight into how educational leadership develops in the context and complexity of schools and community venues prior to enrollment in an educational leadership program. The seven exemplary statements captured some aspects of our department's mission statement, our personal philosophies of education, and perspectives of social justice as a goal, process, and stance (Grant \& Agosto, 2008). We gather these findings into broad themes (types of knowledge) that are evidence of critical literacy toward antioppressive/social justice leadership. We are attentive to the interplay and tension in social justice discourses between individual and 
group needs and aspire toward program development and assessment that considers this relationship. A focus on the collective reveals patterns of social justice leadership among the applicants and in the literature.

\section{DISCUSSION}

We discuss the findings concerning the types of knowledge that characterize the critical literacy practiced among these applicants, that resonate with our understandings of what social justice leadership entails, and that reflect the diversity in what we understand to be practices conducive to social justice and antioppression. These themes reflect the collective types of knowledge that support education about the Other-for the Other-that is critical of privileging and Othering and advocates for transformation: realistic hope, insistence, advocacy, culturally diverse bridge building, and multilevel critique. We also discuss themes that were absent in this composite.

\section{TYPES OF KNOWLEDGE}

Realistic hope. These applicants acknowledged the challenges they have faced with other stakeholders and those with whom they ally. Their successes were students' successes (i.e., increased graduation rate, advanced school grade to a solid C, "they all know how to read FICA"). Their hopes for students were tempered by constraints, as they identified obstacles but were not deterred by them. As Leonardo (2004) asserts, critical social theory in the context of education balances hope and critique.

Advocacy. Across these seven statements, it was clear that they identified those for whom they advocated, why their advocacy was needed, and the vital role they played as educators. They did not lose sight of the people whose futures were at stake. They reflected leadership about the Other and for the Other in combination with other antioppressive approaches. In contrast, there were several statements from the overall sample in which other applicants made no reference to students as they described their leadership experience-for instance, while using data or collaborating with teachers.

Culturally diverse bridge building. These seven applicants served as allies, role models, mentors, and mediators. For instance, they described efforts to serve students and parents who are immigrants, as well as schools and the community. Several "led through example" peers, interns, and parents. Several sought to work in contexts with groups who are diverse in terms of language, ability, and culture and to represent the Others. 
Multilevel critique. Among these seven were examples of critique of self, society, and systems. They recognized the complexity of the issues confronting their realistic hopes. They recognized the multiple factors and actors implicated in student success as well as the particularity of the context and individuals they served. Their attempt to educate for transformation, coupled with critique, was evident as they discussed their commitments and actions toward, for example, "changing paradigms of the crippled system."

Insistence. These candidates reflected on the conditions and attempted to use methods such as collaborative inquiry to create positive changes for students. Their work with Others and for Others involved critique and transformation and can be characterized by the terms persistence, vigilance, and resilience: a "whatever it takes" disposition. Insistence was exemplified in statements such as "I tried everything. Everything worked and everything failed." Where they saw a need, they responded, "The desire [to continue working with students who had made progress] sparked me to create my own program." The link between leadership and commitment was repeated: "As a leader your job is never done." Rather than blaming students and their families, they blamed the inconsistency of programs, neglect, and abuse for students' underpreparedness for academic success.

\section{DISRUPTIVE KNOWLEDGES}

The Othered groups that suffer from injustice would benefit from the poststructural notions of citation and supplementation. Kumashiro (2000) describes these two practices as antioppressive approaches using the example of students who identify using the (altered) term queer to demonstrate agency and political consciousness. Since "critical awareness of the repetition of harmful associations/histories does not actually change them" (p. 42), Kumashiro calls for disruptive knowledge and suggests citation and supplementation, which involve laboring to prohibit harmful associations and histories. These approaches disrupt harmful knowledge and histories through altering the discourse that has constructed queerness in derogatory terms. These processes would equally serve those who identify as intersex, pansexual, two-spirit beings as well as those questioning such categories or evoking more fluid notions and expressions of sexuality, sexual orientation, and gender. An indication of citation is found in Applicant 1 's use of the term crippled. She used the term to describe the educational system as structurally unsound, thereby unsettling or disrupting the mainstream discourse on disability as inherent in people rather than located in the social construction of normality and difference. Another instance was 
Applicant 2's supplementation to harmful discourse on the "foreigner" through providing a rich description of "Mixteco" language and culture. He labored to rework history by disrupting harmful (i.e., stereotypical) knowledge (Kumashiro, 2000) about this particular migrant group.

\section{MARGINALIZED KNOWLEDGES}

While we honor the work and capacities of these applicants, we recognize the absences in their statements as marginalized discourses. Kumashiro (2000) suggests that we examine both what is present and what is missing. While among all 34 applicants, these 7 provided the most substantive discussions of social justice, culture, race, and the achievement gap, there were social groups and aspects of diversity that were not discussed: inequity or disparities related to lesbian, gay, bisexual, or transgendered students, gender, spirituality/religion, and ecojustice. Terminology such as power and oppression were absent, as were frameworks for situating their practice: democratic education, social reconstructionism (Counts, 1932), or antioppressive education (Kumashiro, 2000). These absences make up the null curriculum (Eisner, 1994), or that which is not taught. These are the kinds of absences that faculty can challenge through responsive curriculum and instruction.

Given the strengths and limitation described in these statements, we could craft a program that labors to supplement their knowledge of the absences in their discourse: inequity and disparities related to sexual orientation, sexuality, gender, and spirituality/religion using concepts such as power and oppression and frameworks such as democratic education, social reconstructionism, and antioppressive education. We could aim to enable praxis by offering theory and reflection to support the efforts that leaders make toward change. Through the "cycle of theory, application, evaluation, reflection, and then back to theory" (Freire, 1998, p. 75), we attempt to model through SAFE and other facets of our work to inform program development through a lens of student access, opportunity, and outcomes-broadly defined. The following section reflects how continuous assessment led to our awareness of an outcome concerning the seven exemplary statements (the needles).

\section{WHERE ARE THE NEEDLES?}

After completing both levels of coding, we began a new semester and started to match demographic information to the previously anonymous statements. We noticed that some names were not on our rosters: Where 
were they? Although the "exemplary candidates" were eventually accepted into the program, not all faculty members agreed. Even with the rubric, the divergence of opinion that occurred in the prior selection cycle concerning the selection of applicants of color persisted (Agosto et al., 2010). Although all seven applicants were accepted-that is, those whom we identified as having exemplary statements reflecting a social justice orientation and, therefore, as being most likely to lead from an ethic of social justice-only four enrolled during the next term.

Of the four applicants who enrolled, two were students of color (ethnic and/or racial minority students underrepresented in the university) and two were White. The other three (43\%) who did not enroll in the program identified as Hispanic/Latin@. We inquired into their status and learned that one deferred and the other two withdrew (due to finances, without reason). We were especially curious to know more about the applicant who demonstrated multilevel critique and resisted conformity. This applicant, whose statement of interest inspired us to look more closely, was one of the three students who had not enrolled.

\section{RECOMMENDATIONS}

Given the findings and discussion, we propose several recommendations for our program that might be considered by educational leadership preparation programs with similar aims in response to their context: conduct targeted recruitment (experience, purpose), monitor transition, evoke courageous conversations (Singleton \& Linton, 1995) in committees across divergences and differences, attend to absences, and utilize selection and assessment tools.

Conduct targeted recruitment of experience and purpose. Recruitment that targets aspiring leaders with social justice orientations must be intensive and intentional where so few apply. A low number of applicants who embody a social justice orientation apply and eventually enter our program, which suggests that faculty will need to introduce foundational concepts and theories that others may encounter through life experience or $\mathrm{K}-16$ education. Where few students express social justice orientations or when the only antioppressive perspectives are interjected by faculty or course material (selected by the faculty), there is the risk that oppressive discourses will prevail and few social justice/antioppressive alliances will develop. We recommend targeted recruitment in recognition of the importance of building partnerships and mentoring the next generation of leaders oriented toward social justice who have connections to communi- 
ties and who work from various arenas to positively affect education for all preK-20 students.

Targeted recruitment can occur through identifying administrators in the field who engage in social justice leadership and having them nominate candidates. For instance, nominators can be administrators who are alumni of the program who appeared to value social justice as students. Since several of the applicants oriented toward social justice worked with students typically marginalized, we might recruit applicants working in programs that serve such students or the schools they attend. As a department, we have begun a nomination process across the local districts. We suggest that the department combine the nomination process with targeted recruitment filtered through community organizations and professional development programs focused on related practices, such as culturally relevant leadership.

Given that the exemplary candidates expressed learning about and challenging injustice through their work, perhaps those who are inclined toward social justice leadership are not only those from marginalized communities and social groups but also those who work with students from marginalized communities and social groups and have developed a sense of purpose and success related to justice. We should then ask how purpose can be inspired and a sense of efficacy can be leavened into advocacy and transformation. Such a question on purpose and efficacy could guide the creation of questions, prompts, or cases to inform the selection of applicants.

Monitor transition. An area that also requires a closer look is what happens in the transition from acceptance to enrollment and how programs can provide support (e.g., social, procedural, financial) to facilitate students' enrollment. We have found that at times personal communication between applicants and faculty or staff throughout the application process can be facilitative. In one case, one form was faxed and not received; therefore, the applicant was almost rejected due to an incomplete application package. With a phone call, the misunderstanding was communicated and the final form submitted. Students in the program can serve as mentors who participate in the transition of students from acceptance through enrollment. Financial support for applicants can be awarded to those who have demonstrated social justice leadership advocacy to help in their transition from teacher to teacher paying to attend college. Given that the three students who did not immediately enroll identified as. Hispanic/ Latin@, we might monitor their transition and offer support (financial, relationship, procedural) to students who identify similarly. 
Evoke courageous conversations in committees across divergence and difference. We recommend evaluating applicants holistically with attention to diversity in the composition of the student body being constructed. Those who believe that leadership and education can make a positive difference in people's lives should question what they believe about the role of diversity. This can begin with courageous conversations (Singleton \& Linton, 1995) among faculty regarding their views on diversity, leadership, and equity as well as how they respond to statements in which applicants have dared to write about challenging inequity or have taken the time to contextualize the lives of those for whom they advocate. In our setting, these conversations are few and unplanned. We might inspire dialogue using applicants' statements as prompts. For instance, there was a lack of consensus among committee members on Applicant 6's "leadership potential": the value of her experience with youth ministry. Divergence of opinion invites discussion on conceptions of leadership in relationship to ministry and spirituality.

Attend to absences (i.e., spirituality). Kumashiro (2000) calls for attention to the possibilities of Eastern thought and Buddhism, for instance, while others in education have advocated for more attention to critical spirituality for students (Ryoo, Crawford, Moreno, \& McClaren, 2009) in educational leadership (Dantley, 2003) and at the intersection of race, gender, and social justice leadership (Agosto \& Karanxha, 2011). This candidate inspires us toward courageous conversations among faculty on this question: Which aspects of candidates' identity or political ideology do selection committees look upon (un)favorably? Such conversations should precede the attempt to establish interrater reliability.

Utilize selection and assessment tools. To better understand the impact of the program, we recommend the use of the prompt in the admissions process for generating personal statements and as part of an exit assessment and overall evaluation of educational leadership preparation programs. Specifically, we recommend evaluations of how educational leadership programs foster social (in)justice, such as how the program responds to those who are oriented toward social justice as applicants, candidates, and graduates. Identifying students oriented toward social justice would include monitoring how this orientation develops and transfers between the program and the field.

\section{CONCLUSION}

SAFE calls for an interrogation of supposedly objective criteria: proxies for desert or merit. We concur with Young (1990), who argued that "the 
concepts of domination and oppression, rather than the concept of distribution, should be the starting point for a conception of social justice" ( $p$. 16). As Young posited in her enabling conception of (procedural) justice, "the use of the principle of merit to allocate scarce and desirable positions in a job hierarchy, and in educational institutions that train people for these jobs, is not a value neutral process" (pp. 202-204).

In our search for indications of social justice, we sifted through the seven statements. We further analyzed statements most attentive to the prompt for evidence of critical literacy directed toward antioppressive/ social justice leadership and embodied in practice. This process of searching for indications of a social justice ethic revealed some of our basic assumptions about what social justice entails and helped us to articulate our perspectives on what social justice looks like in practice as indicated by the five broad themes. The applicants' statements tell us about their practice and the context in which they work; they also tell us about our orientations and how they work as filters through which we respond to statements in the process of candidate selection. Sometimes we have to probe to find out who we/Others are, which is an exploration that can be fostered through critical and (multi)culturally relevant curriculum, pedagogy (Ladson-Billings, 1995), evaluation (Prado, 2011), education research (Bogotch \& Schoorman, 2010), and leadership.

Perhaps our own lived experiences growing up in multilingual households have preconditioned us to see the value and beauty in linguistic diversity, code switching, and accents. We are privileged and Othered. We have experienced upward social mobility through the educational pipeline despite our minority positions and histories as women who do not hail from Western Europe. At times we gesture, raise our voices in passion, and even cry. We struggle because we hope; we advocate because we can; and we build bridges across diversity because we see the benefits of diverse relations. We are imperfect people who are learning. The miniportraits of applicants reflect our "partial knowledge" (Kumashiro, 2000) of them and ourselves.

Thus far, we have used SAFE with the standards set forth by the National Center for the Accreditation of Teacher Education as a guide to assess equity and diversity through candidate selection and the rates of rejection for candidates at the intersection of race and gender. We are currently conducting a study on how Black females have experienced the program and whether the social justice mission of the program has affected their current roles as teacher leaders. We continue to inquire into whether our efforts as faculty members advance programmatic equity, whether applicants come to us with a critical social justice ethic, and 
whether-once identified-they are accepted or rejected. The combined effort of self-reflexive research through the multiphase process of SAFE aims to inform program improvement toward becoming more culturally, intellectually, and politically responsive and responsible for equity and the diversity of knowledge, skills, and dispositions represented among incoming and exiting students. We plan to further develop this model and report its implementation in our program as well as continue aspects of assessment that encourage department-wide participation-for instance, by collecting faculty's perceptions of their contributions to fostering the social justice orientation of the program.

In the year since we began conceptualizing SAFE, the program is beginning to benefit from this process, as reflected in course development (culturally relevant leadership), increased diversity among candidates, and the refinement of our application process. Although the original rubric had only four criteria that were overtly related to social justice leadership literature, they are four more than what the program had during the previous cycle of applicant selection. As social justice becomes more central rather than marginalized within departments of educational leadership, we would expect to see social justice orientations take on a more substantive role in the selection criteria of educational leadership programs.

With a change in leadership came a change in the prompt. The master's degree committee is now piloting a prompt that presents a case study but does not ask for direct engagement with the mission statement or the value of equity (see Appendix $\mathrm{C}$ ). While the change in prompt delays our ability to use one longitudinally - that is, in admissions and during an exit assessment-we are still in the testing stage, as this is a new process for us and we have several approaches from which to choose. Regardless of the prompt, guiding frameworks, or stringency of the criteria decided on, the process of interpreting materials for indications of social justice remains an area in need of further research. Additionally, the reconfiguration of the master's committee (changing who is at the table) and changes in personnel disrupted the faculty alliances that produced patterns in the acceptance and rejection rates of candidates in previous selection cycles.

It is still too soon to know whether these changes (prompt related to equity, rubric with explicit social justice related criteria) will become embedded in the culture of the department and its policies. Thus far, discussions concerning issues of equity and justice have been constrained, and the process of using the rubric has not yet been coupled with a deliberative process except in the case where committee members have been tied. The most productive conversations, although constrained, came with the introduction of the rubric, as some faculty worried about who might be 
excluded and whether bilingual and bicultural experiences are assets to leadership.

The broad themes identified have helped to raise questions that inform course development and teaching: How can we inject applicants' experiences with social justice leadership into the curriculum, support their critical literacy, and link their efforts to collective and historical efforts that serve justice? Through this study and its focus on the seven statements, we have excavated multiple expressions and foci of social justice in context that help us resist fashioning or falling victim to an essentialized, hegemonic, and exclusionary notion of social justice.

As decision makers in the process of candidate selection and curriculum alignment, faculty on these committees must work to find a collective sense of what they perceive as "potential," "promise," "professionalism," and worthwhile "purpose"; which characteristics they value; and which types of knowledge, skills and dispositions they perceive as perpetuating (in)justice. This study reinforces assertions in the literature that values and commitments are difficult to change even when people (such as educational leadership faculty) have a guiding document (i.e., rubric, mission statement). We have learned that despite a mission statement and some agreement among faculty piloting a rubric, there is divergence on the nebulous quality of leadership potential and who has it, as well as on the significance of social justice in reforming schools to better serve more students. SAFE reminds us that neither evaluation of a program nor an applicant is neutral, for we cannot extract the instruments we use from the instruments we are.

\section{APPENDIX A: PROMPT 1, 2009-2010}

Describe your a) leadership experience related to aspects of the mission statement, b) interest in the program, and c) goals related to the ideas of equity and diversity.

\section{APPENDIX B: RUBRIC}

Minimum and preferred requirements: Teaching experience in a K-12 school setting, leadership experience (broadly conceived), teaching certification, letter of support (recommendation) from supervisors, evidence of academic success (GPA, GRE, GRADES) and the values, commitments, dispositions, knowledge, and skills that align with the department's Mission Statement. 
Candidate Name:

Committee Member Name:

\begin{tabular}{|l|l|}
\hline REFLECTIVE PRACTICE & + \\
\hline Has reflected on a domain of the profession (list) & \\
\hline Is thoughtful about the meaning of teaching and/or learning & \\
\hline LEADERSHIP CAPACITY AND EXPERIENCE & \\
\hline Has unique and valued talents or leadership experiences & \\
\hline $\begin{array}{l}\text { Brings unique expertise to the leadership domains, cohort, or } \\
\text { program }\end{array}$ & \\
\hline $\begin{array}{l}\text { Demonstrates resiliency (persists despite unusual hardships, } \\
\text { circumstances, disadvantages) }\end{array}$ & \\
\hline COMMITMENT TO EDUCATING ALL STUDENTS & \\
\hline $\begin{array}{l}\text { Is motivated to apply by a commitment to professional } \\
\text { improvement, school improvement, or student success }\end{array}$ & \\
\hline Is preparing to work for the benefit of children/youth & \\
\hline $\begin{array}{l}\text { Advocates justice for traditionally marginalized groups of } \\
\text { students }\end{array}$ & \\
\hline $\begin{array}{l}\text { Quality/ies is/are congruent with the mission statement of the } \\
\text { program }\end{array}$ & \\
\hline $\begin{array}{l}\text { Has experienced a leadership role with students, families, or } \\
\text { organizations, historically underserved in schools }\end{array}$ & \\
\hline $\begin{array}{l}\text { PREPAREDNESS TO LEAD ACROSS DIVERSE } \\
\text { CONTEXTS AND COMMUNITIES }\end{array}$ & \\
\hline $\begin{array}{l}\text { Speaks two or more languages and/or has } 2 \text { or more cultural } \\
\text { backgrounds/identities }\end{array}$ & \\
\hline Has worked or volunteered outside the United States & \\
\hline Quality of writing & \\
\hline $\begin{array}{l}\text { Other asset: } \\
\text { Total +: }\end{array}$ & \\
\hline
\end{tabular}




\section{APPENDIX C: PROMPT 2, 2010-2011}

\section{M.ED. CANDIDATE ADMISSIONS SCENARIO AND QUESTIONS \\ OFFICE OF THE SUPERINTENDENT \\ SCHOOL DISTRICT OF MALIZORNIA}

Date: A Time in the Future

To: New Principal Candidates

From: Ivanna Chexallstuftz, Assoc. Supt.—Golden Lighthouse Public School District

Re: An employment opportunity School District of Malizornia Superintendent, Dr. Hugh Jeego, and I need your assistance: We are seeking to employ a new school principal. The new principal will be one who is well-versed in the intricacies of school-level educational administration, counseling, curriculum, instruction, and policy analyses.

In order for us to choose the best person for the principal's job, the task before each applicant is as follows: Use all of your knowledge, skills, and abilities to provide logical arguments-enhanced by convincing theoretical and empirical evidence-to answer one of questions below:

- Describe and discuss how political efforts of special interest groups could influence education policy in your school.

- Describe and discuss how to develop a plan for collaborating with families and community members that responds to diverse needs of learners in your school.

- Describe and discuss major challenges administrators should be prepared to manage in typical school environments.

- Describe and discuss what is involved in implementing a school curriculum that ensures an adequate education for all learners.

- Describe and discuss whether or not the following budgeting strategy is equitable: Funding is divided evenly among all students in your school; that is, each student enrolled receives $\$ 7,500$ of services.

Please write a cogent memo addressing one of the questions above that is no longer than 2 to 3 double-spaced pages. Please include a cover page listing your name, title of response, and program to which you are applying. Please use Times New Roman font and one-inch margins. Your target audience is the principal's selection committee within the Golden Lighthouse Public School District. 


\section{ACKNOWLEDGMENT}

We are thankful for the insights of the editor and anonymous reviewers of this manuscript and the assistance of graduate student Kathlene Bentley on this project.

\section{REFERENCES}

Agosto, V., \& Karanxha, Z. (2011). Resistance meets spirituality: "I prayed on it." Negro Educational Review.

Agosto, V., Karanxha, Z., \& Bellara, A. (2010). Battling inertia and confronting racial diversity in the echelons of educational leadership. New Orleans, LA: University Council for Educational Administration.

Allan, E. J., \& Estler, S. E. (2005). Diversity, privilege, and us: Collaborative curriculum transformation among educational leadership faculty. Innovative Higher Education, 29(3), 209-232.

Apple, M. W. (2000). Official knowledge: Democratic education in a conservative age (2nd ed.). New York: Routledge.

Apple, M. W. (2001). Educational and curricular restructuring and the neo-liberal and neo-conservative agendas: Interview with Michael Apple. Curriculo sem Fronteiras, 1(1), 1-26.

Bloom, C. M., \& Erlandson, D. A. (2003). African American women principals in urban schools: Realities, (re)constructions, and resolutions. Educational Administration Quarterly, 39(3), 339-369.

Bogotch, I., \& Schoorman, D. (2010). What is a critical multicultural researcher? Self-reflective study of the role of the researcher. Education Citizenship and Social Justice, 5(3), 249-264.

Brooks, J. S., \& Miles, M. T. (2008). From scientific management to social justice ... and back again? Pedagogical shifts in educational leadership. In A. H. Normore (Ed.), Leadership for social justice: Promoting equity and excellence through inquiry and reflective practice (pp. 99-114). Charlotte, NC: Information Age.

.Cambron-McCabe, N., \& McCarthy, M. M. (2005). Educating school leaders for social justice. Educational Policy, 19(1), 201-222.

Cambron-McCabe, N., \& Scheurich, J. J. (2008). From the field: A proposal for educating leaders for social justice. Education Administration Quarterly, 44(1), 111-138.

Capper, C. A., Theoharis, G., \& Sebastian, J. (2006). Toward a framework for preparing leaders for social justice. Joumal of Educational Administration, $44(3), 209-224$.

Chenoweth, T., Carr, C., \& Ruhl, T. (2002, August). Administrator licensure institutions' planning forum: Best practice in education leadership preparation programs. Paper presented at the Administrator Licensure Planning Forum, Eugene, OR.

Counts, G. (1932). Dare the school build a new social order? New York: John Day.

Dantley, M. E. (2003). Critical spirituality: Enhancing transformative leadership through critical theory and African America prophetic spirituality. International Journal of Leadership in Education, 6(1), 3-17. 
Dantley, M. E., \& Tillman, L. (2006). Social justice and moral transformative leadership. In C. Marshall \& M. Oliva (Eds.), Leadership for social justice: Making revolutions in education (pp. 16-30). Boston: Pearson.

Dantley, M. E., \& Tillman, L. C. (2010). Social justice and moral transformative leadership. In C. Marshall \& M. Oliva (Eds.), Leadership for social justice: Making revolutions in education (2nd. ed., pp. 19-33). New York: Pearson.

Eisner, E. W. (1994). The educational imagination: On design and evaluation of school programs (3rd ed.). New York: Macmillan.

Ellsworth, E. (1989). Why doesn't this feel empowering? Working through the repressive myths of critical pedagogy. Harvard Educational Review, 59(3), 297-324.

Foster, W. (1986). Paradigms and promises: New approaches to educational administration. Buffalo, NY: Prometheus Books.

Freire, P. (1998). Pedagogy of freedom. New York: Rowman \& Littlefield.

Furman, G. C., \& Shields C. M. (2005). How can educational leaders promote and support social justice and democratic community in schools? In W. A. Firestone \& C. Riehl (Eds.), A new agenda for educational leadership (pp. 119-137). New York: Teachers College Press.

Grant, C. A., \& Agosto, V. (2008). Teacher capacity and social justice in teacher education. In M. Cochran-Smith, S. Feiman-Nemser, K. E. Demers, \& J. McIntyre (Eds.), Handbook of research on teacher education: Enduring questions and changing contexts (3rd ed., pp. 175-200). New York: Routledge.

Haberman, M., \& Post, L. (1998). Teachers for multicultural schools: The power of selection. Theory Into Practice, 37(2), 96-105.

Hafner, M. M. (2006). Teaching strategies for developing leaders for social justice. In C. Marshall \& M. Oliva (Eds.), Leadership for social justice: Making revolutions in education (pp.167-193). Boston: Pearson.

Jean-Marie, G., Normore, A. E., \& Brooks, J. S. (2009). Leadership for social justice: Preparing 21st century school leaders for a new social order. Journal of Research on Leadership Education, 4(1), 1-31.

Karanxha, Z., Agosto, V., \& Bellara, A. (2010). The hidden curriculum: Candidate diversity in educational leadership and policy preparation. New Orleans, LA: University Council for Educational Administration.

Kumashiro, K. (2000). Toward a theory of anti-oppressive education. Review of Educational Research, 7O(1), 25-53.

Ladson-Billings, G. (1995). Toward a theory of culturally relevant pedagogy. American Educational Research Journal, 32(3), 465-491.

Lather, P. (1991). Getting smart: Feminist research and pedagogy with/in the postmodern. New York: Routledge.

Leonardo, Z. (2004). Critical social theory and transformative knowledge: The functions of criticism in quality education. Educational Researcher, 33(6), 11-18.

Lugg, C. A., \& Shoho, A. R. (2006). Dare public school administrators build a new social order? Social justice and the possibly perilous politics of educational leadership. Journal of Educational Administration, 44(3), 196-208.

Marshall, C., \& Oliva, M. (Eds.). (2006). Leadership for social justice: Making revolutions in education. Boston: Pearson.

Marshall, C., \& Oliva, M. (Eds.). (2010). Leadership for social justice: Making revolutions in education (2nd ed.). Boston: Pearson.

McKenzie, K. B., Christman, D. E., Hernández, F., Fierro, E., Capper, C. A., Dantley, M., et al. (2008). From the field: A proposal for educating leaders for social justice. Educational Administration Quarterly, 44(1), 111-138. 
Merchant, B. M., \& Shoho, A. R. (2010). Bridge people: Civic and educational leaders for social justice. In C. Marshall \& M. Oliva (Eds.), Leadership for social justice: Making revolutions in education (pp. 120-138). Boston: Pearson.

Murphy, J., \& Vriesenga, M. (2006). Research on school leadership preparation in the United States: An analysis. School Leadership and Management, 26(2), 183-195.

Oliva, M., Anderson, G. L., \& Byng, J. (2010). Dilemmas and lessons: The continuing leadership challenge for social justice. In C. Marshall \& M. Oliva (Eds.), Leadership for social justice: Making revolutions in education (2nd ed., pp. 284-312). Boston: Pearson.

Prado, J. (2011). "Honor the context": Opening lines for a critical multicultural evaluative practice. American Journal of Evaluation, 32, 418-427.

Pritchy-Smith, G. (1998). Common sense about uncommon knowledge: The knowledge bases for diversity. Washington, DC: American Association of Colleges for Teacher Education.

Ryan, J., \& Rottman, C. (2007). Educational leadership and policy approaches to critical social justice. Educational Administration and Foundation, 8(1/2), 9-23.

Ryoo, J. J., Crawford, J., Moreno, D., \& McLaren, P. (2009). Critical spiritual pedagogy: Reclaiming humanity through a pedagogy of integrity, community, and love. Power and Education, 1(1), 132-146.

Shoho, A. R. (2006). Dare professors of educational administration build a new order: Social justice within an American perspective. Joumal of Educational Administration, 44(3), 196-208.

Shoho, A. R., Merchant, B. M., \& Lugg, C. A. (2005). Social justice: Seeking a common language. In F. English (Ed.), Handbook of educational leadership (pp. 47-67). Thousand Oaks, CA: Sage Publications.

Singleton, G., \& Linton, C. W. (1995). Courageous conversations about race: Afield guide for achieving equity in schools. Thousand Oaks, CA: Corwin Press.

Skrla, L., Scheurich, J. J., Garcia, J., \& Nolly, G. (2004). Equity audits: A practical leadership tool for developing equitable and excellent schools. Educational Administration Quarterly, $40(1), 133-161$.

Theoharis, G. (2007). Social justice educational leaders and resistance: Toward a theory of social justice leadership. Educational Administration Quarterly, $43(2), 221-258$.

Young, I. M. (1990). Five faces of oppression: Justice and the politics of difference. Princeton, NJ: Princeton University Press.

Vonzell Agosto is an assistant professor in the Department of Educational Leadership and Policy Studies at the University of South Florida. Her research focuses on curriculum, pedagogy, and the leadership preparation toward antioppressive education. She has presented her research at major conferences, including those of the American Education Research Association, University Council for Educational Administration, Bergamo, and the Critical Race Studies in Education Conference. She has published in journals such as the Journal of Negro Education and Teacher Education \& Practice, as well as various handbooks.

Zorka Karanxha is an assistant professor in the Department of Educational Leadership and Policy Studies at the University of South Florida. Her research focuses on leadership for social justice preparation, charter schools, and education law. She has presented her research at major conferences, including those of the American Education Research Association, University Council for Educational Administration, and the Education Law Association. She has published in journals such as Action in Teacher Education and the Journal of Research in Leadership Education. She has coauthored a book, with Perry Zirkel, titled Student Teaching and the Law. 
Copyright of Journal of School Leadership is the property of Rowman \& Littlefield Publishers, Inc. and its content may not be copied or emailed to multiple sites or posted to a listserv without the copyright holder's express written permission. However, users may print, download, or email articles for individual use. 